\title{
KNOWLEDGE, ATTITUDE AND AWARENESS ABOUT FLU VACCINATION AMONG HEALTH CARE PROFESSIONALS OF A TERTIARY CARE CENTRE.
}

KEY WORDS: Influenza, Knowledge, Vaccination.

\section{Amruta V Dashputra*}

R T Badwaik

\section{Archana Borkar}

\section{Amit Date}

Assistant Professor, Pharmacology, NKP Salve Institute of Medical Sciences \& $\mathrm{RC}$ and LMH,Nagpur. *Corresponding Author

Associate professor, Pharmacology, NKP Salve Institute of Medical Sciences \& $\mathrm{RC}$ and LMH,Nagpur.

Professor \& head, Pharmacology, NKP Salve Institute of Medical Sciences \& RC and LMH, Nagpur.

\section{Associate professor, Pharmacology, NKP Salve Institute of Medical Sciences \&} $\mathrm{RC}$ and LMH,Nagpur.

\begin{abstract}
Introduction- Influenza (flu) is a common, highly contagious respiratory disease. Health care professionals (HCPs) are at increased risk of getting infected with this disease. Influenza transmission within health care setting has been widely reported in medical literature. Studies conducted in other countries among HCPs showed poor knowledge and misconceptions about influenza vaccination in participants. This type of study is not found in Indian scenario. Material and Methods- A cross sectional questionnaire based study was conducted at a tertiary health care centre. Study participants were health care providers: doctors and nurses. Results- Majority of participants was not vaccinated against influenza (doctors $83.7 \%$, nurses $88 \%$ ). Doctors (99\%) and nurses (69\%) expressed that influenza is caused by virus and it is transmitted by coughing and sneezing Unlike doctors nurses were not aware about availability of vaccine $(p<0.002)$, they had fear of side effects of vaccine $(p<0.001)$; they did not consider flu as a serious infection $(p<0.008)$. Discussion-Immunization against influenza has been associated with substantial health and economic benefits. Various reasons for not been vaccinated against influenza were stated by doctors and nurses. Influenza vaccine is not included in national immunization schedule like tetanus vaccine and this could also be the reason for low rate of vaccination. Other studies highlighted that low vaccination was because of low vaccine availability and poor knowledge of influenza vaccine and its benefits. Conclusion- Low vaccinations against influenza were found among doctors and nurses. Doctors responded more appropriately regarding influenza symptoms, mode of transmission and about vaccine, route and frequency etc as compared to nurses.
\end{abstract}

\section{INTRODUCTION:}

The $\mathrm{H}_{1} \mathrm{~N}_{1}$ virus that caused pandemic in 2009 is not a regular human flu virus and continues to circulate seasonally worldwide. There are increased epidemics of flu like infectious diseases e.g. seasonal influenza, swine flu with associated complications especially during winter season. Influenza is a common, highly contagious respiratory disease. Health care professionals (HCPs) are at increased risk of getting infected with this disease. HCP can be doctor of medicine, dentist, nurse, physiotherapist, clinical social worker, who is authorized to practice by government authority. Health professionals study, diagnose, treat and prevent human illness, injury and other physical and mental impairment in accordance with the needs of population they serve. HCPs provide treatment and advice based on formal training and experience. ${ }^{1,2}$

Influenza transmission within health care setting has been widely reported in medical literature. ${ }^{3}$ HCPs can serve as carriers for transmission to other patients. ${ }^{1,2}$ Influenza vaccination is the most efficient method of prevention of influenza virus infection and its complications., ${ }^{4,5}$ Flu vaccination in HCPs also improves patient's safety and reduces morbidity and mortality among vulnerable patients. ${ }^{1}$ Therefore World Health Organization (WHO) recommended seasonal and pandemic influenza vaccination for HCPs.

Studies conducted in other countries among HCPs showed poor knowledge and misconceptions about influenza vaccination in participants. ${ }^{1,7}$ This type of study is not found in Indian scenario. Therefore it was thought pertinent to assess the knowledge, attitude and awareness regarding influenza vaccination among HCPs of tertiary care centre. Findings of this study may be helpful for planning strategies to improve flu vaccination among HCPs. This would indirectly affect disease transmission to population and overall improvement of health status of society in general.

\section{MATERIAL AND METHODS:}

A cross sectional questionnaire based study was conducted at a tertiary health care center of central India. Study participants were health care providers of this tertiary care Center which included prescribing physicians, resident doctors and nursing staff. Study was conducted from May 2019 to Dec 2019.

Ethical Approval: Study was conducted after ethical clearance from Institutional Ethics Committee.

The questionnaire was prepared by authors and prevalidated by three senior faculties of the institute. Questionnaire consisted of three parts:

(I) First part comprised of demographic data of participant like age, sex, faculty (doctor / nurse). (II) Second part consisted of 10 items/ statements regarding reasons for not receiving vaccination against $\mathrm{H}_{1} \mathrm{~N}_{1}$ influenza. Each Item was rated on 0-5 Likert scale, and seemed to be suitable for this study. Likert scaling is a bipolar scaling method, measuring either a positive or a negative response to a statement. ${ }^{8} \mathrm{~A}$ score of more or less than three indicates a positive or negative response to a statement respectively. A score of three or very near to three indicate neutral response. The format of a typical five level Likert item is:

1. Strongly disagree (Strongly unfavourable to the concept).

2. Disagree (Somewhat unfavourable to the concept).

3. Neither agrees nor disagrees (undecided).

4. Agree (Somewhat favourable to the concept).

5. Strongly agree (Strongly favourable to the concept).

(III) Third part of the questionnaire covered statements to explore knowledge and understanding of participants about influenza and influenza vaccine. It contained 20 statements having varied types of response like: yes/no, correct /wrong or having options about direct answer.

Participation in the study was on voluntary basis. Participants 
were assured that results of the survey would not have any negative repercussions for them. After explaining purpose of the study, consent of participant was taken. Prescribing physicians, resident doctors $(n=141)$ and nursing staff $(n=34)$ who were involved in clinical work responded to the questionnaire. Anonymity and confidentiality of participants was maintained.

\section{STATISTICAL ANALYSIS:}

Statistical analysis was done by using Epi-info software, version 7. Quantitative data was analyzed using mean score and standard deviation for each item. For qualitative data frequency and percentage was calculated. Regarding inferential statistics, for qualitative data Chi-square test was applied. For quantitative data, unpaired t-test was applied with level of significance $p<0.05$.

\section{RESULTS:}

In present study total 141 doctors (male $48+$ female 93) participated. Average age of doctors was $38.6 \pm 12.12$. Total 34 nursing staff (male $1+$ female 33 ) participated having average age $27.3 \pm 5.44$.

In was found that majority of participants was not vaccinated against influenza (doctors $83.7 \%$, nurses $88 \%$ ), but most of them were vaccinated against tetanus (doctors $96.2 \%$, nurses $90 \%$ ). In this study $99 \%$ of doctors and $69 \%$ of nurses expressed that influenza is caused by virus and it is transmitted by coughing and sneezing. Nurses (70\%) assumed that fever and headache are only symptoms of flu whereas doctors (76\%) thought that there may be variation in presentation of disease. According to doctors (76.72\%) flu includes influenza, swine flu and bird flu whereas nurses (63.4 $\%$ ) had a notion that only influenza means flu.

Regarding knowledge about influenza vaccine $52 \%$ doctors opined that vaccine should be administered every year, $58.13 \%$ stated that two doses should be taken, by i.m. or nasal route whereas nurses said vaccine to be taken once in life time $(60 \%)$, by oral route $(53 \%), 68.34 \%$ of them were not aware about doses.(Table-1)

Tablel: Awareness of health care providers regarding influenza (in percentage)

\begin{tabular}{|l|l|l|l|l|l|}
\hline $\begin{array}{l}\text { Sr. } \\
\text { no }\end{array}$ & Question & Doctors (n=140) & Nurses (n= 34) \\
\cline { 2 - 6 } & Response & & Response & \\
\hline 1 & $\begin{array}{l}\text { Vaccination done in } \\
\text { last 6-12 months } \\
\text { against any disease }\end{array}$ & No & 85.1 & No & 50 \\
\hline 2 & $\begin{array}{l}\text { Vaccination taken } \\
\text { against influenza }\end{array}$ & No & 83.7 & No & 88 \\
\hline 3. & $\begin{array}{l}\text { Name the disease for } \\
\text { which you got } \\
\text { vaccinated }\end{array}$ & Tetanus & 96.2 & Tetanus & 90 \\
\hline 4 & $\begin{array}{l}\text { Influenza is caused } \\
\text { by }\end{array}$ & Virus & 99 & Virus & 69 \\
\hline 5 & Flu is transmitted by & Coughing & 100 & Coughing & 61 \\
\hline 6 & $\begin{array}{l}\text { Symptoms of flu are } \\
\text { All of the } \\
\text { above }\end{array}$ & 76 & $\begin{array}{l}\text { Fever, } \\
\text { Headache }\end{array}$ & 70 \\
\hline 7. & $\begin{array}{l}\text { Routes of } \\
\text { administration of } \\
\text { influenza vaccine }\end{array}$ & IM/Nasal & 59.86 & Oral & 53 \\
\hline 8 & $\begin{array}{l}\text { How many doses of } \\
\text { influenza vaccine } \\
\text { required }\end{array}$ & Two & 58.12 & Don't know & 68.3 \\
\hline 9. & $\begin{array}{l}\text { How often vaccine } \\
\text { should be } \\
\text { administered }\end{array}$ & $\begin{array}{l}\text { Every } \\
\text { year }\end{array}$ & $\begin{array}{l}\text { The } \\
\text { Swine flu, } \\
\text { Bird flu }\end{array}$ & $\begin{array}{l}\text { Once in } \\
\text { life }\end{array}$ & 60 \\
\hline 10. & Flu includes & Influenza & 63.4 \\
\hline
\end{tabular}

In this survey of HCPs regarding reasons for not been vaccinated against influenza, both doctors and nurses disagreed all the reasons mentioned in questionnaire. Though both groups had the same outlook, but statistically significant difference in opinion was found among both groups. Unlike doctors nurses were not aware about availability of vaccine $(p<0.002)$, they had fear of side effects of vaccine $(p<0.001)$; they did not consider flu as a serious infection $(p<0.008)$. Needle fear $(p<0.001)$, storage facility of vaccine $(p<0.005)$ and lack of trained person for drug administration $(p<0.001)$ were also found to be hindering factors for them. (Table-2)

Table 2 : Reasons for not vaccinated against influenza

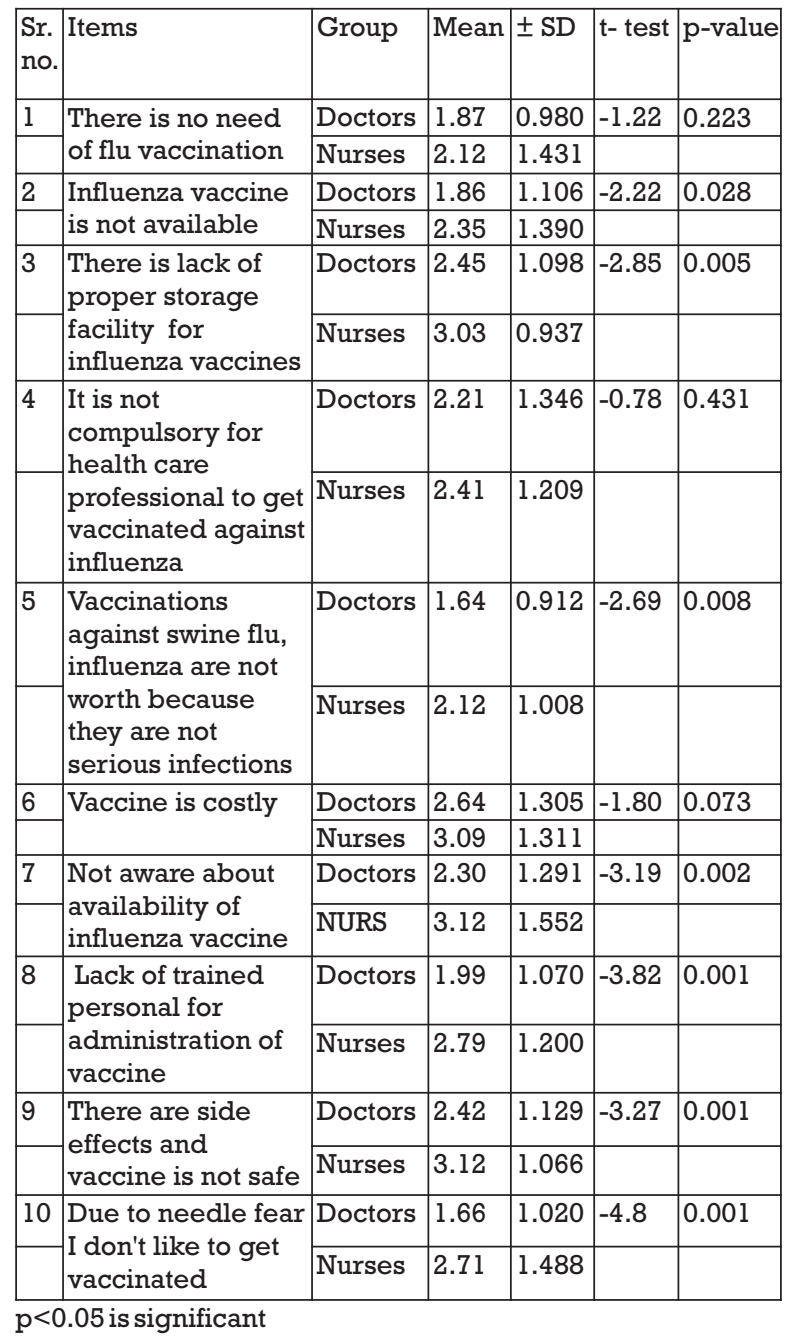

All nurses believed influenza vaccine effective in preventing flu whereas only $75.7 \%$ doctors thought so. Majority in both the groups had conviction that influenza is more serious than common cold and the person can spread influenza even when not having the symptoms and health professionals are more susceptible to influenza than general population. This survey revealed that $78.4 \%$ of doctors agreed with Centre for Disease Control's (CDC) Advisory Committee on Immunization Practices that healthcare professional should receive the flu vaccine whereas most of nurses were not aware of it.

There was difference in the opinion of doctors and nurses that influenza vaccine contains live viruses that may cause influenza (doctors $39 \%$, nurses $73.5 \%$ ) and influenza vaccination does not work in some persons (doctors $49.14 \%$, nurses $82.35 \%$ ). 
Most of the doctors (87\%) thought that symptoms appear 1-7 days after exposure whereas $55.9 \%$ nurses did not think so. (Table-3)

Table 3: Knowledge about influenza and influenza vaccine (in percentage)

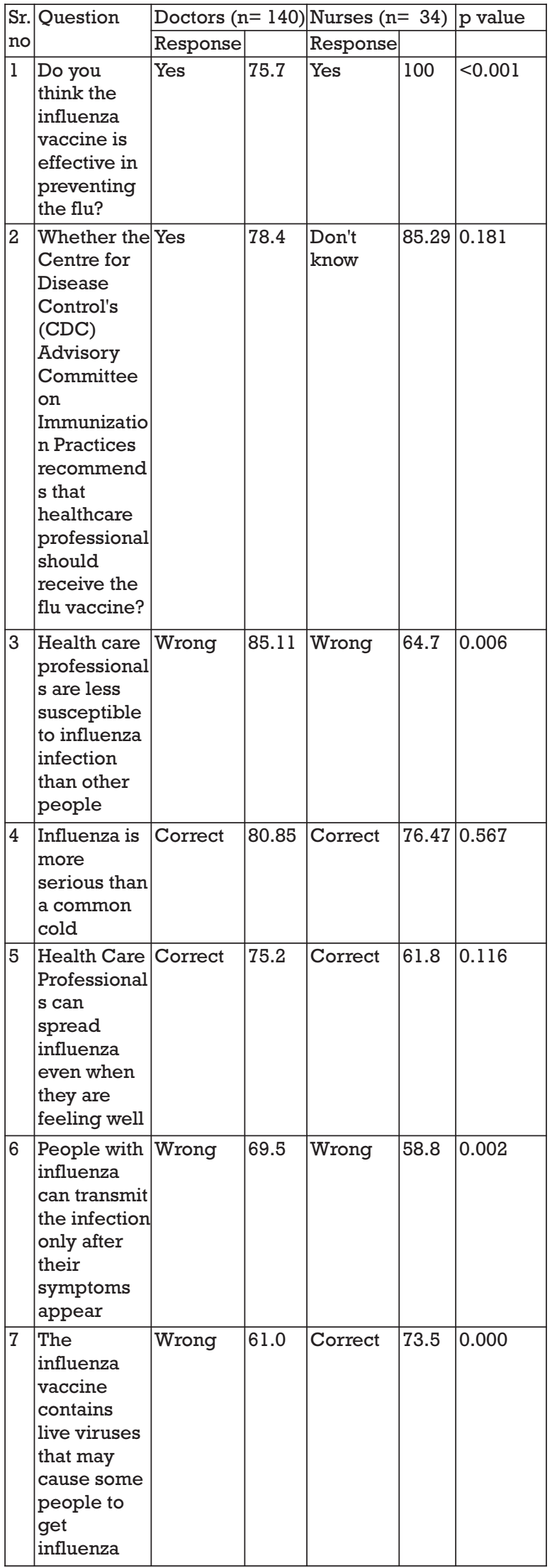

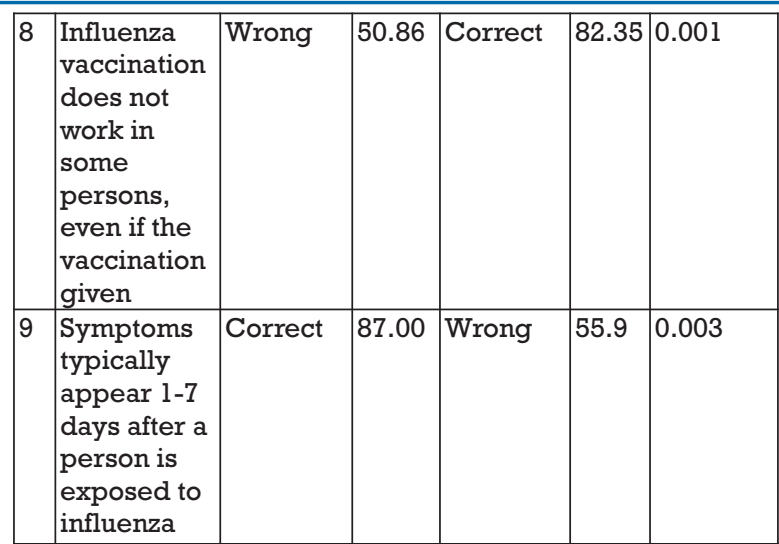

\section{DISCUSSION:}

This study was planned after swine flu (HlNl) epidemic in India in 2016. At that time influenza vaccine was available in market against HINl. If we look back at history; in 2009 swine flu was reported in all over world e.g. United states, Canada, Mexico, Kenya, China, Japan, and many countries of Asia including India. WHO had announced pandemic alert on June 11 2009. Many states of India especially Gujarat, Rajasthan, Maharashtra were worst affected states at that time. ${ }^{9}$ Waves of influenza epidemic come every year in between. In 2016 again there was a surge in cases of flu especially swine flu. ${ }^{10}$

Influenza (flu) is mild to severe respiratory infection. It includes all types of flu like influenza $A$ that is swine flu, bird flu, and simple viral influenza. It is one of most common vaccine preventable diseases affecting people of varied groups. It causes significant levels of illness, may be associated with hospitalization and death. Flu vaccination has been found to be most effective way to prevent infection and severe outcome caused by influenza virus. Immunization against influenza has been associated with substantial health and economic benefits as well as there was reduction in hospital admission by $79 \%$ during influenza epidemics after vaccination. ${ }^{4,5,10,11}$

In this survey of HCPs the reasons put forward by doctors and nurses for not been vaccinated against influenza were in same direction but statistically significant difference in responses was found. Main attributing factors among nurses were lack of awareness about availability of vaccine, side effects of vaccine, needle fear, storage facility for vaccine and lack of trained person for drug administration. Many hindering factors have been found in different studies like fear of adverse reactions, ${ }^{12}$ developing vaccine induced influenza. ${ }^{7,13}$

Study conducted in African and south Asian countries highlighted that low vaccination was because of low vaccine availability and also knowledge about vaccine is low. ${ }^{11}$ In another study low vaccination was largely attributed to the poor knowledge of influenza vaccine and its benefits. ${ }^{14}$

In India after swine flu pandemic in 2009 , there was sudden surge in uptake of vaccine. Uptake of vaccine was higher among HCPs and people with awareness of vaccine. In Indian scenario; data regarding uptake of influenza vaccine among different categories like HCPs, elderly with co morbidity are lacking. ${ }^{10}$

Most of the participants were not vaccinated against influenza. Only $17.7 \%$ doctors \& $6 \%$ nurses were found vaccinated against $\mathrm{H}_{1} \mathrm{~N}_{1}$ influenza in our study. Influenza vaccine is not included in national immunization schedule like tetanus vaccine and this could be the reason for low rate of vaccination. Majority of our participants were vaccinated against tetanus. The same types of results were reported in study conducted in Pakistan. ${ }^{15}$ 
Few more studies conducted in India and other countries showed low rate of vaccination for influenza. ${ }^{7,15,16,17}$ In another study $28.8 \%$ participants (patients) were previously vaccinated on advice of their clinicians. ${ }^{11}$

Influenza vaccine effectiveness can vary from year to year and unfortunately, some people can become infected with a flu virus despite getting vaccinated. Persons who live with or take care of influenza patients are at higher risk for influenzarelated complications. They should get themselves vaccinated especially HCPs. In fact vaccination of HCPs against influenza is an effective intervention to protect them against influenza as well as it decreases morbidity and mortality among the vulnerable patients. ${ }^{5,7,15}$ Vaccination also reduces absenteeism because of illness and improves the health status of HCPs. ${ }^{3,17,18,19}$ In present study, though $78.4 \%$ of doctors trusted guidelines of Centre for Disease Control's (CDC) Advisory Committee on Immunization Practices that healthcare professional should receive flu vaccine, very few of them were vaccinated.

Both the groups according to their clinical experience considered that influenza is more serious than common cold and healthcare professionals are more susceptible to influenza than general population. In a study conducted by Olatunbosun OD only $32.9 \%$ participants responded that influenza was same as common cold and only $29.5 \%$ of participant preferred vaccination as an effective means of preventing serious influenza related complications. ${ }^{11}$

Diseases such as poliomyelitis, tetanus, diphtheria, and pertussis are now rare in world; credit goes to efficacious vaccination campaigns, high hygienic standards and a high standard of living. Public awareness campaigns may be effective in increasing vaccination rates against diseases occurring seasonally like influenza, encephalitis that requires yearly vaccination. Steps should be taken at government level to implement influenza vaccination in national vaccination programme. Same type of recommendations is mentioned in other studies also. ${ }^{15}$ Simultaneously medical records of vaccination administration have to be maintained.

\section{CONCLUSION:}

Low vaccinations against influenza were found among doctors and nurses. Reasons for not been vaccinated against influenza, doctors and nurses had the same outlook, but statistically significant difference in opinion was found. Among nurses adverse effects of vaccine, needle fear and lack of trained person for drug administration were hindering factors for vaccination. Doctors were more appropriate regarding influenza symptoms, mode of transmission and about vaccine, route and frequency etc as compared to nurses.

Since November 2019 the rapid outbreak of corona virus (COVID-19) has become a public health emergency of international concern with enormous adverse impact globally. Whole world is waiting for vaccine against it and it can be hoped that this would increase the awareness about vaccination for diseases which spread widely. It is highly recommended to get vaccinated each year to prevent influenza infection.

\section{ACKNOWLEDGEIMENTS:}

Authors acknowledge support of all the participants in this study and Mr. Jaideep Nayse, Statistician \& Assistant Professor, Department of community medicine for solving statistical hurdle.

\section{RECOMMENDATIONS:}

1. There is a need to increase knowledge and awareness about seriousness of flu and necessity of its vaccination.

2. Strategies to encourage HCPs to get vaccinated are needed. Vaccination screening and administration at workplace may be effective way to provide immunization to health care professionals.

3. Encouragement of high risk patients group to get vaccinated is also needed.

\section{REFERENCES:}

1. Talbot TR, Babbcock H, Caplan AL, Cotton D, Maragakis L L, Poland GA, et al. Revised SHEA position paper: Influenza vaccination of healthcare personal. Infect Control Hosp Epidemiol. 2010;31:987-95.

2. Jordan R, Hayward A. Should healthcare workers have the swine flu vaccine? BMJ 2009;339:b3398

3. Fortaleza CR, Fortaleza CMCB. Knowledge and attitude of health care workers from intensive care units regarding nosocomial transmission of influenza: a study on the immediate pre pandemic period .JVenom Anim Toxins Inc Trop Dis. 2011;17:168-75.

4. Rehmani R, Memon JI. Knowledge, attitude and belief regarding influenza vaccination among healthcare workers in a Saudi hospital.Vaccine. 2010; 28: 4283-7.

5. National Vaccine Advisory Committee. Strategies to achieve the healthy people 2020 annual influenza vaccine coverage goal for health -care personnel: recommendations from the national vaccine advisory committee. Public Health Res. 2013; 128:7-25

6. World Health Organization. Strategic Advisory Group of Experts on Immunization report of the extraordinary meeting on the influenza A (HINl) 2009 pandemic, 7 July 2009. Kly Epidemiol Rec. 2009;84:301-4

7. Khan TM, Khan AU, Ali I,Wu DB-C. Knowledge, attitude and awareness among healthcare professionals about influenza vaccination in Peshawar. Pakistan. Vaccine. 2016;34:1393-8

8. Likert Rensis. A technique for the measurement of attitudes. Archives of Psychology. 1932;140: 1-55

9. Kamate SK, Agrawal A, Chaudhary H, Singh K, Mishra P, Asawa K. Public knowledge, attitude and behavioral changes in an Indian population during the influenza A (HlNl) outbreak. J Infect Dev ctries . 2010;4:7-14

10. Gambhir RS, Pannu PR, Nanda T, Arora G, Kaur A. Knowledge and Awareness Regarding Swine -Influenza A ( $\mathrm{Hl} \mathrm{Nl}$ ) virus infection among Dental Profession in India- A systematic Review.J Clin Diagn Res.2016;10(9) p10- 13

11. Olatunbosun OD, Estehuizen TM, Wiyasonge CS. A cross sectional survey to evaluate knowledge, attitudes and practices regarding seasonal influenza and influenza vaccination among diabetics in Pretoria, South Africa. Vaccine. $2017 ; 35(47): 6375-86$

12. Hofmann F, Ferracin C, Marsh G, Dumas R. Influenza vaccination of healthcare workers: a literature review of attitude and beliefs. Infection. 2006;34:142-7.

13. Manuel D, Henrey B, Hockin J, Naus M. Health behavior associated with influenza vaccination among healthcare workers in long term care facilities. Infect Control Hosp Epidemiol. 2002;23:609-14 .

14. Pfeil A, Mutsch M, Hatz C , Szues TD. A cross -sectional survey to evaluate knowledge, attitude and practice (KAP) regarding seasonal influenza vaccination among European travelers to resourse-limited destinations.BMC Public Health. 2010;10(1):6464-70

15. Ali I, Ijaz M, Rehman I U, Rahim A, Ata H. Knowledge, Attitude, Awareness and Barriers Towards influenza Vaccination Among Medical Doctors at Tertiary Care Health Settingin Peshawar, Pakistan- A cross- Sectional Study. 2018; 15 Jun 27 http://doiorg/10.3389/fpubh.2018

16. Hiremath RN, Kotwal SA, Kunte R, Hiremath S, Basannar D, Bhalla S, Acceptance of vaccination against 2009 pandemic influenza $A$ among health care workers in Pune. Maharashtra. Indian J Public health (2013) 57:48

17. Carman WF, Elder AG,Wallac LA, McAulay K, Walker A, Murray GD, etal. Effects of influenza vaccination of health care workers on mortality of elderly people in long term care: a randomized controlled trial. Lancet (2000)355:937

18. Benet T, Regis C, Voirin N, Robert O, Lina B, Cronenberger S, et al. Influenza vaccination of healthcare workers in acute care hospitals: a case- control study of its effects on hospital acquired influenza among patients. BMC Infect Dis (201212:30 http://www biomedcentral.com 1471-2334/12/30

19. Ballada D, Biasio L, Cascio G, D Alessandro D, Donatelli I, Fara G, etal . Attitude and behavior of health care personnel regarding influenza vaccination. Eur J Epidemiol.(1994) 10:63-8 